\title{
Comparative transcriptomics of THP-1 monocytes in response to different pathogens
}

\author{
Ernst Thuer ${ }^{1,2}$ and Toni Gabaldón ${ }^{1,2,3}$ \\ ${ }^{1}$ Centre for Genomic Regulation (CRG), The Barcelona Institute of Science and Technology, Dr. Aiguader 88, Barcelona 08003, \\ Spain \\ ${ }^{2}$ Universitat Pompeu Fabra (UPF). 08003 Barcelona, Spain. \\ ${ }^{3}$ ICREA, Pg. Lluís Companys 23, 08010 Barcelona, Spain.
}

$\mathrm{U}$ ndifferentiated human monocytes encounter various pathogens while present in the bloodstream. They are considered a primary responder and regulator for human immune reactions. As such, experiments investigating responses to pathogens are often reliant on monocyte cell cultures. For reproducibility reasons, immortalized cell lines are used. One of the most important cell lines used to model pathogen interactions is THP-1, which has been used in a variety of high throughput transcriptomics experiments. Yet as a cancer derived cell line it may no longer maintain its orignial functionality in detecting and responding to pathogens. Using available large scale transcriptomics datasets, we compare the response of THP-1 to a variety of human pathogens; viruses, bacteria, protozoa and fungi. Our approach focuses on the behavior of THP1 in its response to the different pathogens. Our aim is to provide comparative insights into the cell lines, which may serve to potentially improve future experimental design.

\section{Introduction}

Undifferentiated human monocytes reside in the bloodstream for up to three days before differentiating and moving into tissue. During this time, they are a primary responder to any invasive pathogen entering the bloodstream. Due to their primary role in coordinating host responses, they have been suggested as targets for immune augmentations strategies e.g during fungal infections (Segal, 2007). Most experiments investigating bloodstream infections to pathogens rely on the use of immortalized cell lines to reliably and reproducibly model potential interactions between humans and pathogens e.g (Leland and Ginocchio, 2007). A potential downside of such cell lines, usually derived from cancer lines, is that they are established after human cells have already mutated to exhibit unnatural behaviour (Kaur and Dufour, 2012).

A common cell line used to study the behavior of monocytes is the leukemia derived cell line THP-1 (Tsuchiya et al., 1980). This cell line has been used to study a variety of pathogens using RNA sequencing based transcriptomics. Experiments using THP-1 interaction models involve interactions with viruses, Ebola and Marburgvirus (Martinez et al., 2013), Zika (Hanners et al., 2016) and bacteria such as Coxiella burnetii (Millar et al., 2015), Mycobacteria spp. (Reyes et al., 1999; Zakharova et al., 2010) as well as the protist Leishmania mexicana (Millar et al., 2015). In a recent study, Toth et al. (Tóth et al., 2017) Investigated the response of the pathogenic yeast Candida parapsilosis to THP-1. Additionally, available data includes exposure to ethanol, calcitriol and Tissue-type Plasminogen Activator (TPA) (Barendsen, Mueller, and Chen, 1990). To our knowledge, no direct investigation into the comparative response behavior of the cell line THP- 1 has been carried out so far. In this study we hope to provide insights into the behavior of THP-1 if 
bioRxiv preprint doi: https://doi.org/10.1101/155853; this version posted June 26, 2017. The copyright holder for this preprint (which was not certified by peer review) is the author/funder, who has granted bioRxiv a license to display the preprint in perpetuity. It is made available under aCC-BY 4.0 International license.

Comparative transcriptomics of THP-1 monocytes in response to different pathogens

exposed to different human pathogens, and evaluate its ability to develop specific responses. To address how THP1 cells respond to the different stimuli, we investigated transcriptional profiles via RNA sequencing for the human THP1 cell line after exposure to the above mentioned pathogens and chemicals. To reduce analytical bias from the individual experiments, our analysis began with raw RNA sequencing data available at the NCBI Sequence Read Archive for the individual projects. A common, standardized pipeline was applied to carry out the data processing. We focused the subsequent analysis on the inter-project response for the individual pathogens. In order to overcome the very different experimental setups, we relied on more global approaches for tanscriptomic analysis. An important focus was the ability of the cancer derived THP-1 cell lines general response to distinguish the individual pathogens. Specific responses have been investigated in the individual experiments, yet such a variety of pathogens is expected to trigger substantially different overall response pathways. We investigated the impact of the individual pathogens via dimensionality reduction based clustering, and comparative GO term enrichment. Both on large scale to compare the overall behavior of the cells, and on the two available time course analyses to investigate the more minute temporal dynamic of transcription shifting. The available time course analyses comprise the bacterium and intracellular pathogen Mycobacterium abscessus and the yeast Candida parapsilosis. The mycobacteria species consist of a range of bacteria best studied for causing tuberculosis. They are documented to be fast growing and potentially multidrug resistant. The $M$. abscessus complex is also resistant to disinfectants and, therefore, can cause postsurgical and postprocedural infections (Lee et al., 2015). Candida species cause common nosochomial infections (Casadevall and Pirofski, 1999). As yeast, their mechanisms of pathogenicity differs significantly from that of bacteria. The yeast potentially inducing a much weaker response, testing the limits of THP-1 transcriptome adaptation.

\section{Material and Methods}

\subsection{RNA sequencing data processing}

RNA sequencing data was obtained in its raw read format from the Sequence read archive (Leinonen, Sugawara, and Shumway, 2011), with the exception of the data for C. parapsilosis, which was provided by the authors of Toth et al. (Tóth et al., 2017), the full list of sequence runs can be found in Table 1 . A shell script to initiate the full download can be found at the github repository https://github.com/Gabaldonlab/THP1data . After extraction using the sratoolkit. Trimming, for quality pre-processing, of the reads was performed via Trimmomatic v0.32 (Bolger, Lohse, and Usadel, 2014). We mapped the reads using the STAR (Dobin et al., 2013) mapper against the hg38 human reference genome. Human genomic data hg38 v 81., both the reference and annotation files were obtained from UCSC (Ucsc and Browser, 2003). Reads were counted using the htseq package (Anders, Pyl, and Huber, 2015). For the analysis only annotated exons were considered. An overview of samples considered is presented in Table 1 .

\subsection{Data processing}

Read count normalization was performed via transcript per million TPM normalization. R libraries were used to investigate the Principal Components underlying the data variability. The $R$ built in prcomp module and the library FactoMineR (Le, Josse, and Husson, 2008) were used to compute the PCA and cluster estimation respectively. Tree based hierarchical clustering was carried out using the python scipy library. Gene enrichment was analyzed via python scripts available on the projects github https://github.com/Gabaldonlab/THP1data , generating a background model of variance. The enrichment compared to the full human background was carried out using the GOrilla tool (Eden et al., 2009)

\subsection{Visualization}

Visualization was performed via the R module ggbiplot, based on the ggplot2 library, as well as the FactoMineR and superheat plotting function for the respective $R$ scripts. Visualization in python was produced via matplotlib.

\subsection{Enrichment analysis}

Expression enrichment for unregulated genes was computed for each gene on the variance over the non pathogen derived conditions, uninfected cells and separately against the chemicals ethanol and calcitriol. Outliers were tested against a normal distribution using student t-test. The method described by Benjamini \& Hochberg (Benjamini and Hochberg, 1995) was used to correct for multiple testing and evaluate false discovery rate (FDR), in order to correct the resulting p-values. Adjusted p-values of $<0.05$ were considered significant and analyzed by GOrilla against a total background.

\section{Results and Discussion}

As shown in Figure 1 the Principal Component Analysis showed a clear and distinct response to the individual conditions.

This can be considered an important sign that the THP1 cell line has retained its potential for detection of the individual pathogens in initiating individual responses. In a PCA, the abstract underlying effects are quantified and shown on components or axes, with relative strength per axis denoted in percent of variance explained. Individual principal components can show multidimensional response factors. Dimensions are 
bioRxiv preprint doi: https://doi.org/10.1101/155853; this version posted June 26, 2017. The copyright holder for this preprint (which was not certified by peer review) is the author/funder, who has granted bioRxiv a license to display the preprint in perpetuity. It is made available under aCC-BY 4.0 International license.

Comparative transcriptomics of THP-1 monocytes in response to different pathogens

$\begin{array}{lllll}\text { Pathogen } & \text { Sample count } & \text { Time course } & \text { Quality control } & \text { Archive } \\ \text { Mycobacterium bovis } & 14 & \text { No } & \text { failed } & \text { ERR5604 } \\ \text { Mycobacterium abscessus } & 19 & \text { Yes } & \text { pass } & \text { SRR23160 } \\ \text { Zika } & 2 & \text { No } & \text { pass } & \text { SRR51901 } \\ \text { Ebola } & 2 & \text { No } & \text { failed } & \text { SRR16602 } \\ \text { Marburgvirus } & 2 & \text { No } & \text { failed } & \text { SRR16367 } \\ \text { Leishmania mexicana } & 4 & \text { No } & \text { pass } & \text { SRR1562 } \\ \text { Coxiella burnetii } & 4 & \text { No } & \text { pass } & \text { SRR1562 } \\ \text { Candida parapsilosis } & 16 & \text { Yes } & \text { pass } & \text { from author } \\ \text { Staphylococcus aureus } & 9 & \text { No } & \text { failed } & \text { ERR50285 } \\ \text { Non Pathogen } & 5 & \text { No } & \text { pass } & \text { SRR16365 }\end{array}$

Table 1: Table of RNA seq runs processed in the analysis. The columns indicate, in this order: number of samples, pass of the mentioned quality check and accession number.

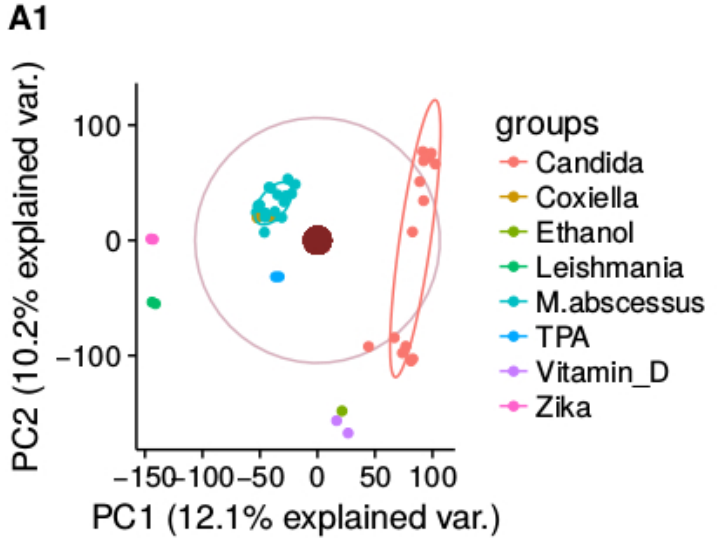

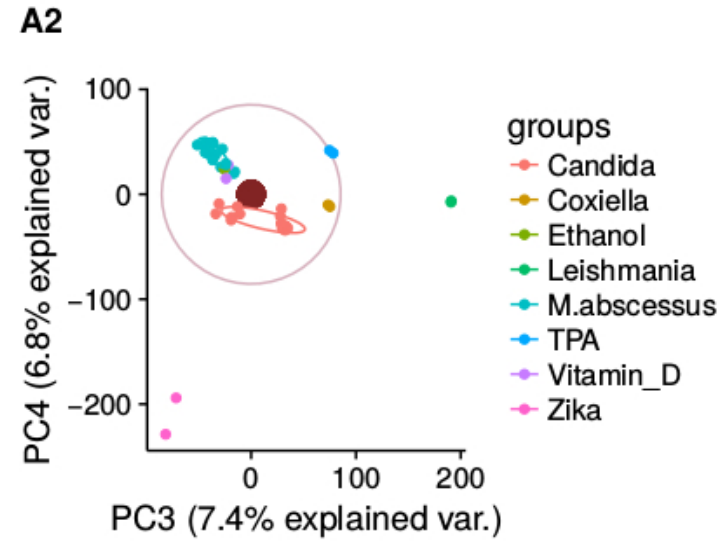

Figure 1: Principal component analysis for all genes, normalized to TPM. Due to the relative low variation per component the first four dimensions are displayed in two 2dimensional plots. Components are displayed in two plots PC1 and 2 in plot A1 and PC3 and 4 in A2. In A1, a cluster separation between the different pathogens and stressors can be observed on the first component. Two clusters comprised of the timeline experiments on M. abscessus and C.parapsilosis are visible along the first axis. A2 seperates viruses more clearly from the protist, as well as the intracellular bacteria Coxiella bruneii and M. abscessus.

visualized in Figure 1 Due to the complexity of analysis, the first four dimensions were considered to explain sufficient variance, collectively accounting for $36.5 \%$ of the observed variance. Similar responses were observed between the intracellular bacterial pathogens Coxiella burnetii and Mycobacterium abscessus, derived from experiments performed by independent groups [Table 1], suggesting that the first components are not influenced by the sequencing but directly by the THP-1 response, the profile of the two strains diverges in the third component showing more nuanced differences in response of THP-1 between the two pathogens.

Overall four distinct response clusters can be observed. With separation of clusters occurring for virus to yeast in the first component, and a distinction of bacteria over the second and third. The intracellular mycobacterium M. abscessus and the yeast $C$. parapsilosis are the most robust groups due to a larger sample size of 19 and 16 runs respectively, and replicates over a time course of infection assay. Factorial analysis to investigate time point responses was therefore limited to those two species. To gain a more detailed view on the minute behavior we investigated the response to the two larger time course analysis. Data was produced for rough and smooth morphologies during exposure times of 1,4 and 24 hours. Although the analysis shows a clear separation (see Figure 2), the primary component derives from the effect between the replicates. The response to C. parapsilosis was less homogeneous, most likely due to the lack of replicates and the overall lower pathogenicity of Candida as compared to Mycobacteria.

In the next step, we quantified overall transcriptional responses against background noise models visualized in Figure 3. Two Noise models were designed. In the first, (background) we used the average counts per gene in uninfected samples, to evaluate the expression compared to an uninfected baseline. For the second model (stressors) we evaluated the average gene count for samples treated with TPA, ethanol and the Vita- 
bioRxiv preprint doi: https://doi org/101101/155853; this version posted June 26, 2017. The copyright holder for this preprint (which was not certified by peer review) is the author/funder, who has granted bioRxiv a license to display the preprint in perpetuity. It is made available under aCC-BY 4.0 International license.

Comparative transcriptomics of THP-1 monocytes in response to different pathogens

M.abscessus 1:2

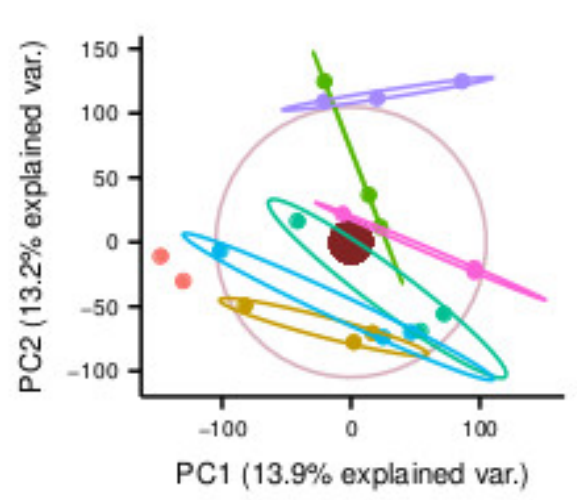

\section{C. parapsilosis 1:2}

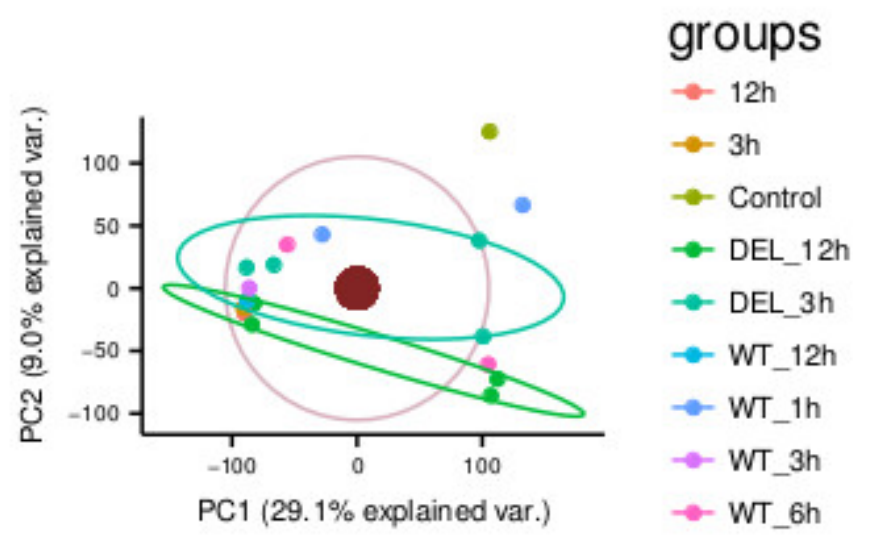

M.abscessus 3:4
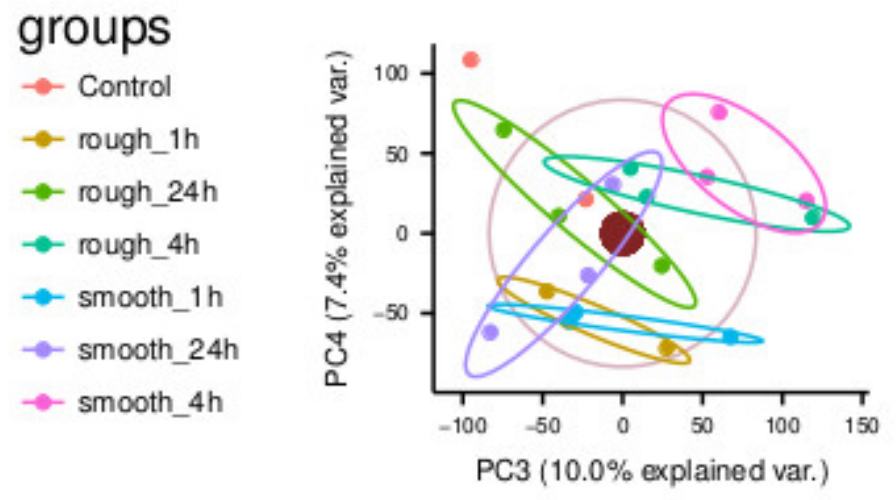

groups

- Control

- rough_1h

- rough_24h

- - rough_4h

- smooth_1h

- - smooth_24h

- - smooth_4h
C. parapsilosis 3:4

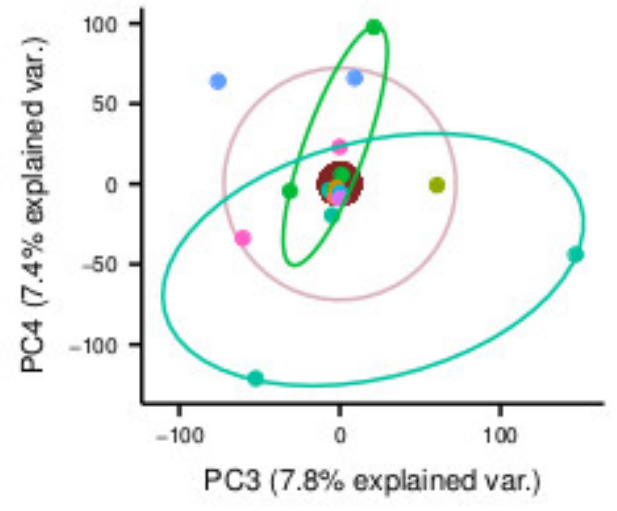

groups

$\rightarrow 12 \mathrm{~h}$

- - 3h

- Control

- DEL_12h

- DEL_3h

- WT_12h

$\rightarrow$ WT_1h

- WT_3h

-WT_6h

Figure 2: PCA of the time course analysis for the infividual sets of M. abscessus (above) and C. parapsilosis (below). Both studies show variance between technical replicates to be responsible for their first component, suggesting a lack of regulation by the THP-1 cells, or rather a lack of designated response. While M. abscessus shows a distinguishable variability over the time course, clustering on $\mathrm{C}$. parapsilosis does not separate the individual conditions. 
bioRxiv preprint doi: https://doi.org/10.1101/155853; this version posted June 26, 2017. The copyright holder for this preprint (which was not certified by peer review) is the author/funder, who has granted bioRxiv a license to display the preprint in perpetuity. It is made available under aCC-BY 4.0 International license.

Comparative transcriptomics of THP-1 monocytes in response to different pathogens

\begin{tabular}{|l|l|l|}
\hline \multicolumn{3}{|c|}{ Mycobacterium abscessus } \\
\hline RNA biosynthetic/metabolic process & defense response to virus & type I interferon signaling pathway \\
\hline \multicolumn{3}{|c|}{ Zika virus } \\
\hline forebrain development & triglyceride catabolic process & neutral lipid catabolic process \\
\hline \multicolumn{3}{|c|}{ Leishmania mexicana } \\
\hline transmembrane transport & ion transport & organic acid transmemb. transport \\
\hline \multicolumn{3}{|c|}{ Coxiella brunetti } \\
\hline & None & \\
\hline & Candida parapsilosis & neutrophil activation \\
\hline mitotic cell cycle process & leukocyte activation &
\end{tabular}

Table 2: GO enrichment of pathogen responses against a stressor background

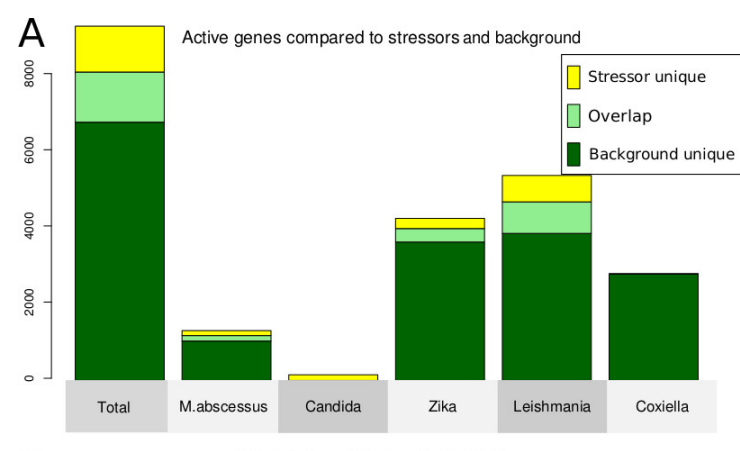

B

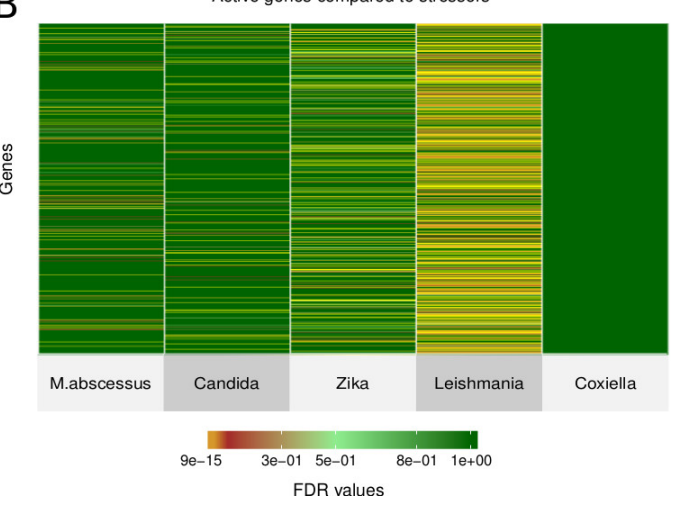

Figure 3: (A) Barplot visualizing the quantification of response against the two background models. Unique responses in yellow and dark green are only observed against the specific background. Overlap in light green shows responses similar between stress and uninfected cells. (B) shows a heatmap of individual genes actively regulated in the 5 species against the stress response. Notably, Coxiella burnetii shows no significantly enriched genes against the stressor subset.

min D metabolite calcitriol to evaluate basic stress responses. Individual genes were tested for upregulation only against the model genes, returning a value of significance per gene and pathogen. This methods ignores experimental design in order to generalize the various experiments. Figure 3 shows the overlap between the background and stressor comparison. In total, 9302 genes were activated in any pathogen response compared to both backgrounds, with 1318 genes overlapping between the noise models. 6780 and 1204 genes were unique to the background and stressors model, respectively. This indicates an active response by THP-1, and its ability to distinguish uninfected surroundings to chemical stimuli.The cells show a clear distinction between the responses to the individual pathogens. Yet, the THP-1 response to $C$. parapsilosis shows no significant difference to the background model, but does present a distinction to the stressors model. C. parapsilosis, as a pathogenic yeast, is often commensal e.g (Gabaldon, Naranjo-Ortiz, and Marcet-Houben, 2016), and seemingly does not provoke a general strong transcriptomic response in the host. Interestingly, compared to the stressor background, only the M. abscessus cells show a classified defense response. According to GO terms, the response is antiviral [Table 2].

An antiviral response to $M$. abscessus is partially expected, due to the related $M$. tuberculosis ability to trigger Interferon responses (Prabhakar et al., 2003), and Interferon production in general T-cell reponses (Belardelli and Gresser, 2010). L. mexicana shows the strongest overall response. With 3861 more genes activated than in the background, and a response of 694 unique genes to the $L$. mexicana stress compared to the stressor background. GO enrichment using GOrilla visualized in Table 2 shows unique responses for the pathogens. Most notably, the most enriched GO term for Zika is GO:0030900, pertaining to anatomical structure and forebrain development. This is in line with Zikas clinical symptoms, such as microcephalus as described in this review (Paixo et al., 2016). Enrichment for $L$. mexicana showed active genes involved in iron transport, an observation in line with Huynh et aliis (Huynh, Sacks, and Andrews, 2006) discovery of iron transporters being essential for parasitic reproduction. Active Iron transportation could therefore be an expected host response.

\section{Conclusion}

Our analysis suggests that the THP-1 cell line is capable of distinguishing various cellular stresses, and provide individual responses to various chemicals and pathogens. It accurately portraits gene enrichment for e.g Zika clinical symptoms. The large scale transcrip- 
bioRxiv preprint doi: https://doi.org/10.1101/155853; this version posted June 26, 2017. The copyright holder for this preprint (which was not certified by peer review) is the author/funder, who has granted bioRxiv a license to display the preprint in perpetuity. It is made available under aCC-BY 4.0 International license.

Comparative transcriptomics of THP-1 monocytes in response to different pathogens

tomic response is uniquely different for each analyzed experiment, and the cells show similar responses to the intracellular pathogens e.g Coxiella burnetii and Mycobacterium abscessus. Yet, the experimental resolution is less pronounced in more detailed experiments. Time course analysis using THP- 1 showed a stronger variation between technical replicates than the actual experimental course. A recent study by Schurch et al (Schurch et al., 2016) estimates the number of true positives in RNA sequencing with 3 replicates to be between 20 and $40 \%$. Using the first components as indicators of variance, we estimate that at least $12 \%$ of the total variance are attributed to technical variation. By using general probabiliy, we can estimate the true positives for triplicates to be between 13.6 and $27.26 \%$ using THP- 1 cells ( according to $\left(1-(1-\alpha)^{n}\right)$ ). Therefore, especially for the investigation of pathogens with an expected mild response, additional replicates are strongly recommended.

\section{Bibliography}

Anders, Simon, Paul Theodor Pyl, and Wolfgang Huber (2015). "HTSeq-A Python framework to work with high-throughput sequencing data". In: Bioinformatics 31.2, pp. 166-169. ISSN: 14602059. DOI: 10.1093/bioinformatics/btu638.

Barendsen, N, M Mueller, and B. Chen (1990). "Inhibition of TPA-induced monocytic differentiation in THP-1 human monocytic leukemic cells by staurosporine, a potent protein kinase $\mathrm{C}$ inhibitor." In: Leuk Res. 5, pp. 467-74.

Belardelli, Filippo and Ion Gresser (2010). "The neglected role of type I interferon in the T-cell response: implications for its clinical use". In: Immunology Today 8, pp. 369-72.

Benjamini, Yoav and Yosef Hochberg (1995). "Controlling the False Discovery Rate: A Practical and Powerful Approach to Multiple Testing ". In: Journal of the Royal Statistical Society 57.1, pp. 289-300.

Bolger, Anthony M., Marc Lohse, and Bjoern Usadel (2014). "Trimmomatic: A flexible trimmer for Illumina sequence data". In: Bioinformatics 30.15, pp. 2114-2120. ISSN: 14602059. DOI: 10.1093/ bioinformatics/btu170.

Casadevall, A and L Pirofski (1999). "Host-pathogen interactions: redefi ning the basic concepts of virulence and pathogenicity". In: Infection and immunity 67.8, pp. 3703-3713. ISSN: 0019-9567.

Dobin, Alexander et al. (2013). "STAR: Ultrafast universal RNA-seq aligner". In: Bioinformatics 29.1, pp. 15-21. ISSN: 13674803. DOI: $10.1093 /$ bioinformatics/bts635.

Eden, Eran et al. (2009). "GOrilla: a tool for discovery and visualization of enriched GO terms in ranked gene lists". In: BMC Bioinformatics 10.1, p. 48. ISSN: 1471-2105. DOI: 10.1186/1471-2105-10-48. URL: http://www . biomedcentral.com/1471-2105/10/ 48.

Gabaldon, Toni, Miguel A. Naranjo-Ortiz, and Marina Marcet-Houben (2016). "Evolutionary genomics of yeast pathogens in the Saccharomycotina". In: FEMS Yeast Research 16.6, pp. 1-10. IssN: 15671364. DOI: 10.1093/femsyr/fow064.

Hanners, Natasha W. et al. (2016). "Western Zika Virus in Human Fetal Neural Progenitors Persists Long Term with Partial Cytopathic and Limited Immunogenic Effects". In: Cell Reports 15.11, pp. 2315-2322. ISSN: 22111247. DOI: $10.1016 / \mathrm{j}$. celrep . 2016 . 05. 075. URL: http://dx.doi.org/10.1016/j . celrep.2016.05.075.

Huynh, Chau, David L. Sacks, and Norma W. Andrews (2006). "A $<\mathrm{i}>$ Leishmania amazonensis $</ \mathrm{i}>$ ZIP family iron transporter is essential for parasite replication within macrophage phagolysosomes". In: The Journal of Experimental Medicine 203.10, pp. 2363-2375. ISSN: 0022-1007. DOI: 10.1084/ jem . 20060559. URL: http : / / www . jem . org / lookup/doi/10.1084/jem.20060559.

Kaur, Gurvinder and Jannette M Dufour (2012). "Cell lines: Valuable tools or useless artifacts." In: Spermatogenesis 2.1, pp. 1-5. ISSN: 2156-5554. DOI: 10. 4161/spmg . 19885. URL: http : / /www . ncbi . nlm . nih.gov/pubmed/22553484\$ \backslash\$nhttp : //www . pubmedcentral.nih.gov/articlerender . fcgi?artid=PMC3341241.

Le, Sebastien, Julie Josse, and Francois Husson (2008). "FactoMineR: An R Package for Multivariate Analysis". In: Journal of Statistical Software 1. Dor: 10. 18637/jss.v025.i01.

Lee, Meng Rui et al. (2015). "Mycobacterium abscessus complex infections in humans". In: Emerging Infectious Diseases 21.9, pp. 1638-1646. IssN: 10806059. DOI: $10.3201 /$ eid2109.141634.

Leinonen, Rasko, Hideaki Sugawara, and Martin Shumway (2011). "The sequence read archive". In: Nucleic Acids Research 39.SUPPL. 1, pp. 2010-2012. ISSN: 03051048. DOI: 10.1093/nar/gkq1019.

Leland, Diane S. and Christine C. Ginocchio (2007). "Role of cell culture for virus detection in the age of technology". In: Clinical Microbiology Reviews 20.1, pp. 49-78. ISSN: 08938512. DOI: 10 . 1128/CMR . 00002-06.

Martinez, O. et al. (2013). "Ebola Virus Exploits a Monocyte Differentiation Program To Promote Its Entry”. In: Journal of Virology 87.7, pp. 3801-3814. ISSN: 0022-538X. DOI: 10 . 1128/ JVI . $02695-12$. URL: http://jvi .asm . org/cgi/doi/10.1128/ JVI. 02695- 12 .

Millar, Jess A et al. (2015). "Coxiella burnetii and Leishmania mexicana residing within similar parasitophorous vacuoles elicit disparate host responses." In: Frontiers in microbiology 6.August, p. 794. ISSN: 1664-302X. DOI: $10.3389 / \mathrm{fmicb} .2015 .00794$. URL: http://journal . frontiersin .org/article/10. 3389/fmicb. 2015.00794/abstract. 
bioRxiv preprint doi: https://doi.org/10.1101/155853; this version posted June 26, 2017. The copyright holder for this preprint (which was not certified by peer review) is the author/funder, who has granted bioRxiv a license to display the preprint in perpetuity. It is made available under aCC-BY 4.0 International license.

Comparative transcriptomics of THP-1 monocytes in response to different pathogens

Paixo, Enny S. et al. (2016). "History, epidemiology, and clinical manifestations of Zika: A systematic review". In: American Journal of Public Health 106.4, pp. 606-612. ISSN: 15410048. DoI: 10.2105/AJPH. 2016.303112.

Prabhakar, Savita et al. (2003). "Inhibition of Response to Alpha Interferon by Mycobacterium tuberculosis". In: Infect Immun 5, 2487-2497.

Reyes, Leticia et al. (1999). "Effects of Mycoplasma fermentans incognitus on differentiation of THP-1 cells". In: Infection and Immunity 67.7, pp. 31883192. ISSN: 00199567.

Schurch, Nicholas J. et al. (2016). "How many biological replicates are needed in an RNA-seq experiment and which differential expression tool should you use?" In: Rna 22.6, pp. 839-851. IssN: 1355-8382. DOI: $10.1261 / \mathrm{rna} .053959 .115$. arXiv: 1505.02017. URL: http : / / rnajournal . cshlp . org / lookup / doi/10.1261/rna.053959.115.

Segal, Brahm H (2007). "Role of macrophages in host defense against aspergillosis and strategies for immune augmentation." In: The oncologist 12 Suppl 2.Supplement 2, pp. 7-13. IsSN: 1083-7159. DOI: 10. 1634 / theoncologist . 12 - S2 - 7. URL: http : //theoncologist. alphamedpress.org/content/ 12/suppl\{\_\}2/7.full.

Tóth, Adél et al. (2017). "Investigation of Candida parapsilosis virulence regulatory networks following host-pathogen interaction". In: PLOS Pathogen, submitted.

Tsuchiya, S et al. (1980). "Establishment and characterization of a human acute monocytic leukemia cell line (THP-1)". In: Int J Cancer, pp. 171-6.

Ucsc, The and Genome Browser (2003). "The UCSC Genome Browser". In: Curr Protoc Bioinformatics, pp. 1-23. DOI: 10 . 1002/0471250953 . bi0104s28. The.

Zakharova, Ekaterina et al. (2010). "Mycoplasma suppression of THP-1 cell TLR responses is corrected with antibiotics". In: PLoS ONE 5.3, pp. 3-6. ISSN: 19326203. DoI: $10.1371 /$ journal. pone. 0009900. 